\title{
Data envelopment analysis in service quality evaluation: an empirical study
}

\author{
Seyedvahid Najafi $\cdot$ Saber Saati $\cdot$ Madjid Tavana
}

Received: 20 May 2014/ Accepted: 30 September 2014/Published online: 10 October 2014

(C) The Author(s) 2014. This article is published with open access at Springerlink.com

\begin{abstract}
Service quality is often conceptualized as the comparison between service expectations and the actual performance perceptions. It enhances customer satisfaction, decreases customer defection, and promotes customer loyalty. Substantial literature has examined the concept of service quality, its dimensions, and measurement methods. We introduce the perceived service quality index (PSQI) as a single measure for evaluating the multiple-item service quality construct based on the SERVQUAL model. A slack-based measure (SBM) of efficiency with constant inputs is used to calculate the PSQI. In addition, a nonlinear programming model based on the SBM is proposed to delineate an improvement guideline and improve service quality. An empirical study is conducted to assess the applicability of the method proposed in this study. A large number of studies have used DEA as a benchmarking tool
\end{abstract}

\section{S. Najafi}

Department of Industrial Engineering South Tehran Branch, Islamic Azad University, Tehran, Iran

e-mail: s.vahid_najafi@yahoo.com

\section{S. Saati}

Department of Mathematics Tehran-North Branch,

Islamic Azad University, Tehran, Iran

e-mail: ssaatim@yahoo.com

\section{Tavana ( $\square)$}

Business Systems and Analytics Department, Lindback Distinguished Chair of Information Systems and Decision Sciences, La Salle University, Philadelphia, PA 19141, USA e-mail: tavana@lasalle.edu

URL: http://tavana.us/

\section{Tavana}

Business Information Systems Department, Faculty of Business Administration and Economics, University of Paderborn, 33098 Paderborn, Germany to measure service quality. These models do not propose a coherent performance evaluation construct and consequently fail to deliver improvement guidelines for improving service quality. The DEA models proposed in this study are designed to evaluate and improve service quality within a comprehensive framework and without any dependency on external data.

Keywords Data envelopment analysis - Slack-based measure $\cdot$ Service quality $\cdot$ Perceived service quality index $\cdot$ SERVQUAL model

\section{Introduction}

Tourism is an engine of growth in many developing countries and contributes to foreign earnings more than many other economic sectors. Customer satisfaction is one of the most important sources of competitive advantage in tourism and service quality has an important influence on customer satisfaction (Martín-Cejas 2006). Delivering service with a high level of perceived quality can enhance customer loyalty, thus improving customer retention $(\mathrm{Hu}$ et al. 2009). The effect of service quality on customer satisfaction and its influence on gaining competitive advantage is undeniable (Yang et al. 2011). Although many studies have been conducted to identify the most important dimensions of service quality, the research on the comprehensive evaluation of service quality has been limited. We propose a systematic and structured framework for service quality evaluation in the hospitality industry which can also be extended to a wide range of industries in the service sector of the economy. The proposed performance measurement system uses data envelopment analysis (DEA) to evaluate a set of peer entities called decision- 
making units (DMUs). DEA is a non-parametric mathematical modeling technique which requires very few assumptions and can be used in performance evaluation problems with complex relations between multiple inputs and multiple outputs. DEA can be used to provide a holistic view of service quality which is composed of multiple-item constructs.

The service quality measurement methods in the literature can be broadly categorized into two groups: incidentbased and attribute-based methods (Stauss and Weinlich 1997). The incident-based methods capture and analyze the customer incident data during various contact situations (Ro and Wong 2012). The attribute-based methods measure the quality of service on different dimensions. The SERVQUAL instrument is one of the most popular attribute-based research methods used in service quality measurement (Chou et al. 2011; Gilbert and Wong 2003; Lupo 2013; Tsang and Qu 2000). The SERVQUAL instrument is widely used by both academics and practitioners despite numerous criticisms directed at the scale (Caruana et al. 2000). A great deal of literature has explored different ways of defining service quality, considering a variety of dimensions and measurement methods. We introduce the perceived service quality index (PSQI) as a single measure for evaluating the multiple-item service quality construct based on the SERVQUAL model. A DEA model with constant inputs is used to calculate the PSQI. Moreover, a non-linear programming (NLP) model is developed to suggest guidelines for elevating service quality to a desirable level. DEA models have been used in the literature to measure service quality, but they do not provide a coherent performance evaluation construct and thus fail to delineate improvement guidelines for improving service quality.

Assaf and Magnini (2012) used the distance stochastic frontier method and a balanced sample of leading hotel chains in the US to measure the hotel efficiency scores and examine the effects of customer satisfaction on the hotel rankings. They concluded that there is a significant difference between the efficiency results derived from the models that include customer satisfaction and those that exclude customer satisfaction.

Sigala (2004) illustrated the value of stepwise DEA for measuring and benchmarking hotel productivity as well as the advantage of using DEA for measuring service quality. She also analyzed some broader issues regarding productivity measurement. She extended the current DEA applications by developing a stepwise approach to DEA that combined correlation with DEA analysis. Chang (2008) investigated the relationship between service quality and customer value, and explored the internal composition of this relationship in the hotel industry. Functional value was found to be affected mainly by reliable instances and accuracy of service quality, whereas conditional value was influenced by the responsiveness of service quality. Furthermore, emotional value was found to be affected mainly by the empathy engendered by service quality, while social value was influenced by tangible instances of service quality. Finally, epistemic value is affected by the responsiveness of service quality. Monfared and Safi (2013) developed a novel two-stage network DEA model to evaluate the relative efficiency of teaching quality and research productivity in universities. The proposed model was tested at Alzahra University in Iran and showed that it performs better than three alternative single-stage models.

Hsieh and Lin (2010) utilized relational network DEA to construct a model to analyze the efficiency and effectiveness of international tourist hotels in Taiwan. They evaluated the different production processes within the hotel and studied the relationships between efficiency, effectiveness, and overall performance. Finally, they recommended ways for enhancing the overall performance of the hotel industry in Taiwan. Cheng et al. (2010) improved the SBM of efficiency in context-dependent DEA and applied and measured the performance of selected hotels in Taiwan. They conducted an empirical study and concluded that the market differentiates five performance levels forming the benchmark structure for the hotel in their study. Hsieh et al. (2010) applied DEA to measure the operational efficiency and effectiveness in the Taiwanese hotel industry. Their proposed performance measurement model used the multi-criteria optimization and compromise solution method (Opricovic 1998) combined with measuring the entropy of the weights of the criteria.

Chiu et al. (2010) used DEA to investigate the operating efficiency of Taiwanese Hotels under different efficient frontier systems. They concluded that the efficiency of chain-operated hotels is higher than the efficiency of independent-operated hotels; assessing different frontier systems in the same way can misrepresent an efficient reference set; and some inefficient hotels are mistaken as being efficient if the hotels are treated as independent samples. Shyu and Hung (2012) developed a three-stage DEA model for the hotel industry in Taiwan. Three models were tested to explore the operation factors determining the management performance. Their empirical results showed that group operation is not the main determinant of operation efficiency of international tourist hotels, whereas small-scale hotels and chain hotels have significantly superior operational efficiency. They showed that using their three-stage DEA model, the management can avoid inefficient resource distribution decisions and enhance managerial efficiency. Talluri et al. (2013) examined the compatibility of operating efficiency and service quality by utilizing a combination of DEA and survey-based empirical research methods in the service driving agencies based on the actual transaction data. Their analysis revealed 
important strategic decision-making implications for service operations managers and provided novel insights for academic research. A large number of studies have used DEA as a benchmarking tool to measure service quality. These models do not propose a coherent performance evaluation construct and consequently fail to deliver improvement guidelines for improving service quality. The DEA models proposed in this study are designed to evaluate and improve service quality within a comprehensive framework and without any dependency on external data. Subjective variables have been widely used in mathematical models in different studies such as market analysis (Nasrabadi et al. 2013), decision making (Hosseini and Tarokh 2013) and service quality evaluation (Soteriou and Stavrinides 1997).

The remainder of this paper is organized as follows. In "Literature review", we review the service quality evaluation models in the literature. In "Data envelopment analysis", we present the mathematical details of the DEA model proposed in this study. In "Empirical study", we present an empirical study to demonstrate the applicability and exhibit the efficacy of the procedures in the proposed method. "Conclusion and future research directions" outline our conclusions and future research directions.

\section{Literature review}

Service quality models

Considering three main characteristics of services: intangibility, heterogeneity and inseparability, it is difficult to assess service quality. There are many tangible ways to judge goods quality, but tangible evidence is limited in the assessment of equipment, facilities and employees. In the absence of tangible aspects, customers must consider other intangible aspects of services. Consequently, the evaluation of this elusive and indistinct construct becomes very difficult (Parasuraman et al. 1985). Several attempts have been made to conceptualize service quality constructs. A common approach among researchers is to compare customer expectations with his/ her perceptions of services (Grönroos 1984; Parasuraman et al. 1985).

Among various proposed constructs, the SERVQUAL scale has been widely used by researchers in various service industries. Parasuraman et al. (1985) conducted an exploratory qualitative study using focus group interviews with customers and in-depth interviews with the executives. They developed a multi-item conceptual model of service quality based on a set of gaps so that the fifth gap (the gap between expected service and perceived service) is a function of the gaps related to the service provider side. They proved that perceived service quality is the result of the consumer's comparison of expected service with perceived service.

Parasuraman et al. (1985) proposed a SERVQUAL scale with 5 dimensions (i.e., reliability, tangibles, responsiveness, empathy, and assurance) and 22 items for assessing service quality and balancing customer perceptions and expectations as follows:

- Reliability performing and fulfilling services accurately and as they promise.

- Tangibles appearance and tidiness of facilities, assets and personnel.

- Responsiveness accountability and willingness of personnel's and providing prompt services.

- Empathy taking individualized notice and intimacy with customers.

- Assurance setting up trust in customers and competence of employees to inject confidence to customer.

According to Parasuraman et al. (1985), the service quality is a function of perception and expectation of customers and can be modeled as:

$\mathrm{SQ}_{i}=\sum_{j=1}^{k}\left(P_{i j}-E_{i j}\right)$

where:SQ $=$ Overall perceived service quality by individual $i, P=$ Perception of individual $i$ with respect to service quality item $j, E=$ Expectation of individual $i$ with respect to service quality item $j$, and $K=$ Number of attributes.

Negative gaps mean perceived quality is less than satisfactory, zero gaps mean service quality is satisfactory and positive gaps mean perceived service quality is more than satisfactory (Parasuraman et al. 1985). The service quality literature shows that SERVQUAL as a standard scale for assessing service quality has been used to a large extent by researchers and service providers and has attracted a great deal of attention in recent years (Mei et al. 1999).

\section{Hotel service quality}

The hotel industry is highly sensitive to economic cycles due to demand fluctuation (Chen and Yeh 2011). The lack of service quality standards and the constant interactions between guests and employees have added more complexity to service quality evaluation in the hotel industry. Hoteliers, who once were concerned about the tangible aspect of their operations are now more concerned about service quality improvement. In a highly competitive 
tourism and hotel market environment, it is necessary for hoteliers to learn about their customer expectations and take corrective measures to improve their services and customer satisfaction.

Several studies have been conducted in the hotel industry to explore the service quality dimensions from the customer's viewpoint. Some of them reported the usual five dimensions of SERVQUAL construct for service quality in hotels (Fick and Ritchie 1991; Knutson et al. 1990). Other studies explored different dimensions for hotel service quality (Akan 1995; Akbaba 2006; Ekinci et al. 1998; Mei et al. 1999; Saleh and Ryan 1991; Wilkins et al. 2007). Recently, Kuo et al. (2012) studied problem solving, empathy, enthusiasm and friendliness as a way to measure hotel service quality; and Ladhari (2011) explored tangibility, reliability, responsiveness, confidence and communication as hotel service quality dimensions.

Related literature shows that dimensions of hotel service quality may differ from one segment of the hotel industry to another (Akbaba 2006). The literature also shows that expectations of hotel service quality differ from culture to culture (Armstrong et al. 1997), and some personal factors such as nationality affect customer expectation in the hotel industry services (Ariffin and Maghzi 2012).

Considering concerns about using SERVQUAL in hotel industry, an extensive study was done in nine five star hotels in Tehran, Iran to investigate the dimensions of hotel service quality from the customer viewpoint. Using exploratory factor analysis, five service quality dimensions of "tangibles", "problem solving", "service supply", "empathy", and "security" were identified. The validity and reliability of the scale were also verified (Najafi et al. 2013). Table 1 shows the five dimensions and their respective service quality attributes.

Methods for evaluating service quality

Assessing service quality using the SERVQUAL scale has been conducted by several researchers. The analysis of SERVQUAL data has also been done through an item-byitem and dimension-by-dimension analysis based on the gap method (Buttle 1996). The most frequently used methods for SERVQUAL evaluation are statistical analysis, multi-criteria decision making, fuzzy set theory, and DEA.

Statistical methods have been traditionally applied to compare customer's expectations and perceptions of services. As an instance, in a study conducted by Akbaba (2006) in the hotel industry, the paired-samples $t$ tests between the respective expectation means and perception means of all service quality attributes showed that they were significantly different. Similar methods for evaluating service quality have been applied in different contexts such
Table 1 Dimensions and items of hotel service quality

\begin{tabular}{|c|c|c|}
\hline Dimension & Item & \\
\hline \multirow[t]{8}{*}{ Tangibles } & Q1 & $\begin{array}{l}\text { Internal decoration (floor, ceilings, } \\
\text { furniture, corridors) is stylish }\end{array}$ \\
\hline & Q2 & $\begin{array}{l}\text { External hotel region (gardens, parking, } \\
\text { buildings) is scenery }\end{array}$ \\
\hline & Q3 & $\begin{array}{l}\text { Hotel is outfitted with modern and easy to } \\
\text { use equipment }\end{array}$ \\
\hline & Q4 & $\begin{array}{l}\text { Facilities and equipment of rooms are } \\
\text { comfortable, clean and relaxing }\end{array}$ \\
\hline & Q5 & $\begin{array}{l}\text { Equipment works well without any } \\
\text { breakdown }\end{array}$ \\
\hline & Q6 & Public areas are quite clean \\
\hline & Q7 & $\begin{array}{l}\text { Food and beverage served is completely } \\
\text { sanitary }\end{array}$ \\
\hline & Q8 & Employees' appearance is always neat \\
\hline \multirow[t]{6}{*}{ Service supply } & Q11 & Employees Never linger guests \\
\hline & Q15 & Hotel tries to minimize all delays \\
\hline & Q16 & The hotel keeps records accurately \\
\hline & Q17 & $\begin{array}{l}\text { All materials needed to provide services are } \\
\text { enough }\end{array}$ \\
\hline & Q21 & $\begin{array}{l}\text { Employees always treat politely especially } \\
\text { when quests complain }\end{array}$ \\
\hline & Q23 & $\begin{array}{l}\text { Hotel services scheduling is flexible and } \\
\text { proportionate to guests }\end{array}$ \\
\hline \multirow[t]{6}{*}{ Empathy } & Q24 & The hotel tries to support guests in conflicts \\
\hline & Q25 & $\begin{array}{l}\text { Employees notice to guests before they } \\
\text { require }\end{array}$ \\
\hline & Q26 & $\begin{array}{l}\text { Employees try to provide pleasant } \\
\text { experience by heart }\end{array}$ \\
\hline & Q27 & $\begin{array}{l}\text { Employees give individualized attention to } \\
\text { guests }\end{array}$ \\
\hline & Q28 & $\begin{array}{l}\text { The hotel's services are in accordance with } \\
\text { guests' needs and desire }\end{array}$ \\
\hline & Q29 & $\begin{array}{l}\text { Employees understand customers' specific } \\
\text { needs rapidly }\end{array}$ \\
\hline \multirow[t]{6}{*}{ Problem solving } & Q9 & Employees seem young \\
\hline & Q10 & $\begin{array}{l}\text { Employees are willing to solve guests' } \\
\text { problems }\end{array}$ \\
\hline & Q12 & $\begin{array}{l}\text { Employees know when and how services } \\
\text { provide }\end{array}$ \\
\hline & Q13 & $\begin{array}{l}\text { Employees listen to customers' requests } \\
\text { with patience }\end{array}$ \\
\hline & Q14 & Guests can easily express their criticism \\
\hline & Q18 & All services completed as promised \\
\hline \multirow[t]{3}{*}{ Security } & Q19 & $\begin{array}{l}\text { Hotel completely protects the personal } \\
\text { privacy of the guests }\end{array}$ \\
\hline & Q20 & $\begin{array}{l}\text { All security measures are considered by } \\
\text { hotel }\end{array}$ \\
\hline & Q22 & $\begin{array}{l}\text { Guests have trust and confidence to } \\
\text { Employees }\end{array}$ \\
\hline
\end{tabular}

as private hospitals (Zarei et al. 2012), the banking industry (Kumar et al. 2009), the airline industry (Chau and Kao 2009), and the education industry (Bahadori et al. 2011). 
Saleh and Ryan (1991) investigated the application of SERVQUAL in the hotel industry and found that the gap between expectation and perception in the services offered is a source of guests' dissatisfaction. Other researchers not only analyzed the gap but also explored the meaningful dimensions in hotel service quality using factor analysis (Akbaba 2006; Kuo et al. 2012; Saleh and Ryan 1991). Various regression models have also been developed to assess the relative importance of the factors in predicting customer satisfaction with the service quality offered by the particular hotels (Akan 1995; Akbaba 2006; Mei et al. 1999). Ladhari (2009) examined the validity and reliability of lodging quality index using data gathered from 200 Canadian respondents who had stayed in a hotel in Canada. Their quality index structure suggests that "tangibility" and "communication" are the most important dimensions in predicting "overall service quality", "cognitive satisfaction", "emotional satisfaction", "recommendation", "loyalty", and "willingness to pay a premium price".

Similarly, other studies have been conducted to explore the casual relationship between hotel service quality and the other related salient variables using structural equation modeling (Kwortnik and Han 2011). Batista et al. (2014) investigated the impact of service quality on customer satisfaction and loyalty among hotel customers. Results showed that hotel service quality and handling guest complaints are the most influential variables in guest satisfaction.

Other researchers have used multi-criteria decision making for SERVQUAL assessment. This category of studies focuses on prioritizing service quality attributes using different decision-making matrices and measurements with alternatives and attributes (Chen 2011; Lin 2010).

Shieh et al. (2010) identified major criteria of hospital service quality and causal relationships among them in Taiwan using SERVQUAL. They then used the decisionmaking trial and evaluation laboratory (DEMATEL) to identify the importance of each criterion to the management of the hospital. Awasthi et al. (2011) presented a hybrid approach based on SERVQUAL and fuzzy TOPSIS and evaluated service quality of four metro lines in Montreal. Using fuzzy TOPSIS, the alternatives were ranked based on the overall performance score of service quality. Chou (2009) proposed a multiple criteria decision-making method based on SERVQUAL for the evaluation of airport service quality by considering the importance weight of each service item. Fuzzy set theory has also been used in service quality research. Chien and Tsai (1998) measured the gap between customer's satisfaction and importance of quality items using the Hamming distance and Dubois's method instead of using difference scores (perceptions minus expectations). Wu et al. (2004) applied a fuzzy linguistic framework to measure the overall effectiveness of linking the market position and strategy of service quality for five hospitals. Chou et al. (2011) established a fuzzy weighted SERVQUAL model for evaluating the service quality and a case study of Taiwanese airline was conducted to illustrate the proposed fuzzy weighted SERVQUAL model.

Satapathy and Mishra (2013) introduced a framework for system design requirements in electricity utility service to measure service quality. They used artificial neural network to find the important areas for improvement and applied quality function deployment to design a new electricity industry. They then used interpretive structural modeling to assess the relationship between the design requirements. Zoraghi et al. (2013) employed a fuzzy multi-criteria decision-making model to evaluate service quality in hotels. They considered both subjective and objective weights to rank five hotels in Tehran. Three experts expressed their opinion on the alternatives according to seven service quality criteria. Their subjective method considered the expert judgments and fuzzy numbers were applied to deal with the ambiguity of their judgments. On the other hand, their objective method determined the criteria weights by mathematical modeling. The results showed the relative merits of their proposed model over similar methods in the literature.

Carrasco et al. (2012) developed a fuzzy model based on semantic translation under the perspective of the SERVQUAL instrument and assessed the quality of e-financial services.

More recently, DEA has also been used to measure service quality in the service sector of the economy. Manandhar and Tang (2002) categorized DEA models for benchmarking of bank branches into "operating efficiency", "service quality efficiency", and "profitability efficiency".

The service quality efficiency models often focus on the use of resources in providing service quality to customers (Bessent et al. 1984; Chilingerian and Sherman 1990; Sherman and Zhu 2006; Soteriou and Stavrinides 1997; Soteriou and Zenios 1999). Soteriou and Stavrinides (1997) developed a service quality model that can be used to assess the degree of optimal utilization resources and bank branches. Their study does not attempt to develop service quality measures, but rather tries to show how such measures can be incorporated into a model that can provide guideline towards service quality improvement. The model inputs consist of consumable resources such as the number of personnel, working space, time, and the number of account types. The output of the model is the perceived service quality of the branch personnel. The benchmarking of branches is based on how well they convert resources to 
achieve the level of service quality perception from the personnel viewpoint.

Lee and Kim (2014) proposed a DEA model based on SERVQUAL/SERVPERF to measure the overall service quality in firms using five dimensions of SERVQUAL/ SERVPERF as outputs. In this model, the overall service quality of a DMU is not measurable unless it is benchmarked with some other DMUs. In addition, this relative single measure does not show the total service quality of a firm, because customer expectations have not been considered in their model.

\section{Data envelopment analysis}

DEA is a non-parametric mathematical programming method for measuring the relative efficiency of DMUs with multiple inputs and outputs that does not require any assumptions about a priori information on the importance of inputs and outputs. The advantage of non-parametric approaches is that they do not assume functional forms of the frontier. The definition of a DMU is generic and flexible and includes different consumable or non-consumable inputs and outputs. A set of weights are determined and the outputs and inputs are aggregated separately with regard to these weights to form a ratio as efficiency (Cooper et al. 2007).

Consider $n$ DMUs, each transforming varying amounts of $m$ different inputs to produce $s$ different outputs. Specifically, $\mathrm{DMU}_{\mathrm{p}}$ consumes amount $x_{i p}$ of input $(i=1, \ldots, m)$ and produces amount $y_{r p}$ of output $(r=1, \ldots, s)$. Assume that $x_{i j} \geq 0$ and $y_{r j} \geq 0$ and each DMU has at least one positive input and one positive output value. The standard input-oriented Charnes-Cooper-Rhodes (CCR) model is:

$\operatorname{Max} \sum_{r=1}^{s} \mu_{r} y_{r p}$

Subject to:

$\sum_{r=1}^{s} \mu_{r} y_{r j}-\sum_{i=1}^{m} v_{i} x_{i j}=1 \quad \forall j$

$\sum_{i=1}^{m} v_{i} x_{i p}=1$

$\mu_{r}, v_{i} \geq 0 \quad \forall r, i$

The standard CCR models allow each DMU to obtain the best weights and efficiencies (Charnes et al. 1978). The original DEA model measures the efficiency of DMUs radially and it does not consider slack values while the SBM is a non-radial method that measures the efficiency based on the slack values. A SBM efficiency score is introduced to calculate the efficiency and slack values together. The SBM efficiency index $\rho$ is obtained from the following fractional problem in terms of slack values (Tone 2001).

$\min \rho=\frac{1-(1 / m) \sum_{i=1}^{m} s_{i}^{-} / x_{i p}}{1-(1 / s) \sum_{r=1}^{s} s_{r}^{+} / y_{r p}}$

subject to:

$\sum_{j=1}^{n} \lambda_{j} x_{i j}+s_{i}^{-}=x_{i p} \quad \forall i$

$\sum_{j=1}^{n} \lambda_{j} y_{r j}-s_{r}^{+}=y_{r p} \quad \forall r$

$\lambda_{j}, s_{i}^{-}, s_{r}^{+} \geq 0 \quad \forall j, i, r$

The index $\rho$ has a value between 0 and 1. A DMU is efficient if and only if $\rho^{*}=1$. In this case, all slacks of the respective DMU are zero and the DMU is located on the efficient frontier. The above formulation can be transformed into a linear program using the Charnes-Cooper transformation (Tone, 2001) as follows:

$\min \tau=t-(1 / m) \sum_{i=1}^{m} \bar{x}_{i} / x_{i p}$

subject to:

$1=t+(1 / s) \sum_{r=1}^{s} \bar{y}_{r} / y_{r p}$

$t x_{i p}=\sum_{j=1}^{n} \Lambda_{j} x_{i j}+\bar{x}_{i} \quad \forall i$

$t y_{r P}=\sum_{j=1}^{n} \Lambda_{j} y_{r j}-\bar{y}_{r} \quad \forall r$

$\Lambda_{j}, \bar{x}_{i}, \bar{y}_{r} \geq 0 \quad \forall j, i, r$

$t>0$

The optimal solution for the above LP is $\left(\tau^{*}, t^{*}, \Lambda_{j}^{*}, \bar{x}_{i}^{*}, \bar{y}_{r}^{*}\right)$ and the optimal solution of the SBM can be defined as:

$\rho^{*}=t^{*}, \lambda_{j}^{*}=\Lambda_{j}^{*} / t^{*}, s_{i}^{-*}=\bar{x}_{i}^{*} / t^{*}, s_{j}^{+*}=\bar{y}_{j}^{*} / t^{*}$

Although DEA was originally developed for measuring efficiency of DMUs that consume several inputs to produce several outputs, DEA plays a broader role, as a tool for solving multiple criteria decision-making problems (Bouyssou 1999) and dealing with subjective variables. Also in the study model, the inputs do not transform into the outputs directly. Some DEA models require consistent input and output data (either high or low) (Lee and Kim 2012, 2014). A CCR model with a single constant input (or a single constant output) coincides with the corresponding Banker-Charnes-Cooper (BCC) model (Lovell and Pastor 1999). The CCR models without inputs (or without outputs) are meaningless. Pure output models have been used in different contexts such as service benchmarking (Lee 
and Kim 2012, 2014; Seol et al. 2007) and the application of target testing of bank services (Lovell and Pastor 1997). This study applies a model with constant inputs to aggregate the service quality perception into a single measure.

Model configuration for service quality evaluation

Grönroos (1982) identified two dimensions for service quality: technical quality and functional quality. Functional quality refers to the quality of service delivery, while technical quality indicates the outcome of the service. Quality evaluations are not only made solely on the outcome of a service; but also they involve the assessment of service delivery process (Parasuraman et al. 1985).

Customers with a certain amount of expectations come to receive a certain service. Their expectation of a service has been affected by word of mouth, personal needs and past experiences (Parasuraman et al. 1985). The key factor which determines the level of perceived quality is the process of service delivery. The DEA approach is an appropriate method for dealing with quality evaluation because service quality is a multiple-item construct and customers' evaluation is based on the process of service delivery.

In this paper, a DEA model is proposed to deal with service quality evaluation using the SERVQUAL method. We use a SBM of efficiency with constant inputs to calculate the PSQI. The SBM of efficiency is selected in this study because it allows for considering the slacks in the model and dealing with input excess and output shortfall directly. As a result, we can easily measure the exact amount of improvement needed with respect to each service quality attribute.

We define two DMUs and refer to them as the expectation and perception DMUs. The expectation and perception DMUs are used to determine the quality of services. To operationalize the model, the expectations and perceptions means of service quality items are considered as outputs, and a constant value of virtual input, 1, is assigned as the inputs of the DMUs. To measure PSQI, the following linear form of the SBM is considered:

$\min P S Q I=t-(1 / k) \sum_{i=1}^{k} \bar{x}_{i}$

subject to:

$$
\begin{aligned}
& 1=t+(1 / k) \sum_{r=1}^{k} \bar{y}_{r} / P_{r} \\
& t=\Lambda_{1}+\Lambda_{2}+\bar{x}_{i} \quad \forall i \\
& t P_{r}=\Lambda_{1} E_{r}+\Lambda_{2} P_{r}-\bar{y}_{r} \quad \forall r \\
& \bar{x}_{i}, \bar{y}_{r} \geq 0 \quad \forall i, r \\
& \Lambda_{j} \geq 0 \quad j=1,2 \\
& t>0
\end{aligned}
$$

where $E_{r}$ and $P_{r}(r=1, \ldots, k)$ denote the expectations and perceptions means of $k$ service quality items, respectively, and $\bar{x}_{i}, \bar{y}_{r}$ are the slack values. The PSQI is the efficiency of the perception DMU. It is important to note that only one of the DMUs is efficient at the same time. The following NLP formulation is developed based on SBM to propose suggestions for improving the service quality at a target or desired PSQI (DPSQI) level.

$\operatorname{Min}\left\{\operatorname{Max}\left(g_{i}\right)\right\} \quad \forall i$

subject to:

$1=D P S Q I+(1 / k) \sum_{i=1}^{s} s_{i} / P_{i}^{\prime}$

$E_{i}-P_{i}^{\prime}=g_{i} \quad \forall i$

$s_{i}=D P S Q I . g_{i} \quad \forall i$

$P_{i}^{\prime} \geq P_{i} \quad \forall i$

$s_{i}, g_{i} \geq 0 \quad \forall i$

The above model with minimax objective function consists of $i$ variables. $g_{i}$ can be modeled as a single linear programming using one additional variable $c$ and $i$ additional constraints as follows (Eiselt and Sandblom 2007):

Min $c$

subject to:

$c \geq g_{i} \quad \forall i$

$1=\mathrm{DPSQI}+(1 / k) \sum_{i=1}^{k} s_{i} / P_{i}^{\prime}$

$E_{i}-P_{i}^{\prime}=g_{i} \quad \forall i$

$s_{i}=$ DPSQI. $g_{i} \quad \forall i$

$P_{i}^{\prime} \geq P_{i} \quad \forall i$

$c, s_{i}, g_{i} \geq 0 \quad \forall i$

A firm with customer expectations $E_{i}(i=1, \ldots, k)$ and perceptions $P_{i}(i=1, \ldots, k)$ for $k$ service quality attributes should raise its customers' perceptions to $P_{i}^{\prime}(i=1, \ldots, k)$ to reach a given level of DPSQI. In cases where the firm attempts to fully fill the gaps, the DPSQI $=1$, and the target level of customer perceptions is $E_{i}=P_{i}^{\prime}(i=$ $1, \ldots, k)$. Obviously, improvement efforts can be considered when the PSQI $<1$. Commonly, customers tend to rate their expectation high (Babakus and Boller 1992) and it is impossible to eliminate service quality gap completely in many service contexts. Therefore, in this model the DPSQI is considered less than 1 to represent a more realistic level for the service quality.

Tone (2001) defined the reference set of linear SBM model as the set of indices corresponding to positive $\lambda_{j}$ to $\left(x_{0}, y_{0}\right)$. The reference set $R_{0}$ is:

$R_{0}=\left\{j \mid \lambda_{j}^{*}>0\right\} \quad(j \in\{1, \ldots, n\})$. 
Table 2 The demographics of respondents $(N=210)$

\begin{tabular}{|c|c|c|}
\hline Attribute & Frequency & Percen \\
\hline \multicolumn{3}{|l|}{ Gender } \\
\hline Male & 71 & 149 \\
\hline Female & 29 & 61 \\
\hline \multicolumn{3}{|l|}{ Marital status } \\
\hline Married & 71 & 149 \\
\hline Single & 23.3 & 49 \\
\hline Other & 5.7 & 12 \\
\hline \multicolumn{3}{|l|}{ Age } \\
\hline $18-24$ & 9 & 19 \\
\hline $25-34$ & 18.6 & 39 \\
\hline $35-44$ & 19 & 40 \\
\hline $45-54$ & 20.5 & 43 \\
\hline $55-64$ & 18.1 & 38 \\
\hline 65 or above & 14.8 & 31 \\
\hline \multicolumn{3}{|l|}{ Career } \\
\hline Government employee & 16.2 & 34 \\
\hline Self-employed & 62.4 & 131 \\
\hline Retired & 13.8 & 29 \\
\hline Student & 6.2 & 13 \\
\hline Housewife & 0.5 & 1 \\
\hline Other & 1 & 2 \\
\hline \multicolumn{3}{|l|}{ Education level } \\
\hline Illiterate & 0.5 & 1 \\
\hline Elementary & 7.6 & 16 \\
\hline Junior high school & 6.7 & 14 \\
\hline High school & 19 & 40 \\
\hline B.S/B.A & 46.7 & 98 \\
\hline M.S/M.A & 14.3 & 30 \\
\hline Ph.D & 5.2 & 11 \\
\hline \multicolumn{3}{|l|}{ Purpose } \\
\hline Remedial & 10 & 21 \\
\hline Business & 69 & 145 \\
\hline Recreation & 12.9 & 27 \\
\hline Research & 4.8 & 10 \\
\hline Other & 3.3 & 7 \\
\hline \multicolumn{3}{|l|}{ Frequency of staying at hotels } \\
\hline Less than once a year & 10 & 21 \\
\hline Once a year & 2.4 & 5 \\
\hline Twice a year & 11.4 & 24 \\
\hline Three times a year & 26.7 & 56 \\
\hline Four times a year & 21.9 & 46 \\
\hline Five times or more a year & 27.6 & 58 \\
\hline \multicolumn{3}{|l|}{ Annual income (US Dollar) } \\
\hline Below 1,000 & 1 & 0.5 \\
\hline $1,001-3,000$ & 22 & 10.5 \\
\hline $3,001-5,000$ & 87 & 41.4 \\
\hline $5,001-7,000$ & 77 & 36.7 \\
\hline $7,001-9,000$ & 20 & 9.5 \\
\hline
\end{tabular}

Table 2 continued

\begin{tabular}{lll}
\hline Attribute & Frequency & Percent \\
\hline $9,001-12,000$ & 3 & 1.4 \\
Above 12,000 & 1 & 0.5 \\
\hline
\end{tabular}

The reference set of the linear SBM model (4) can be similarly defined as follows:

$R_{0}=\left\{j \mid \Lambda_{j}^{*}>0\right\} \quad(j \in\{1, \ldots, n\})$.

We can suggest improvements when the perception DMU is inefficient or on the other hand PSQI $<1$. In this case, the first DMU (expectation) is efficient and emerges as the reference set for the second DMU (perception), therefore, $\Lambda_{2}$ is equal to zero. Since virtual values are assigned as the inputs of the DMUs, access of inputs is meaningless. We replace $P_{i}(i=1, \ldots, k)$ with $P_{i}^{\prime}(i=1, \ldots, k)$, put $\Lambda_{2}$ and $\bar{x}_{i}(i=1, \ldots, k)$ equal to zero in Model (6), and transformed it to a NLP model.

\section{Empirical study}

An empirical study was conducted to assess the service quality of a five star international hotel situated in Tehran, Iran. A questionnaire with five dimensions and 29 items was designed based on the SERVQUAL. The SERVQUAL questionnaire uses a five-point Likert ranging from "very low" to "very high". In addition, the demographic attributes of the guests were also recorded in this questionnaire. The study samples were drawn from the pool of guests who stayed in this five star hotel in 2012. 300 questionnaires were administered to the hotel guests. Questionnaires were given to hotel guests on their day of departure. 90 questionnaires were not usable due to incomplete information and the remaining 210 questionnaires were processed for the purpose of this study resulting in a $70 \%$ response rate. Table 2 presents the profile of the respondents and Table 3 presents the mean expectations, perceptions, and gaps of the service quality items.

\section{Evaluation of hotel service quality}

The SERVQUAL model was used to assess customer perceptions and expectations with regards to the five service quality dimensions and then evaluated the service quality by analyzing the gap between them. DEA was used on the collected data using the SERVQUAL method. The mean expectations and perceptions of 29 quality items were considered as the outputs of the expectations and perceptions DMUs, respectively, and the constant values of 
Table 3 Mean expectations, perceptions and gaps of the service quality items $(N=210)$

\begin{tabular}{|c|c|c|c|c|}
\hline Dimension & Item & $\begin{array}{l}\text { Perceptions } \\
\text { mean }\end{array}$ & $\begin{array}{l}\text { Expectations } \\
\text { mean }\end{array}$ & $\begin{array}{l}\text { Rounded } \\
\text { gap means }\end{array}$ \\
\hline \multirow[t]{8}{*}{ Tangibles } & Q1 & 3.84 & 4.93 & -1.09 \\
\hline & Q2 & 3.87 & 4.94 & -1.07 \\
\hline & Q3 & 3.81 & 4.91 & -1.10 \\
\hline & Q4 & 3.87 & 4.95 & -1.08 \\
\hline & Q5 & 3.93 & 4.96 & -1.03 \\
\hline & Q6 & 3.85 & 4.91 & -1.06 \\
\hline & Q7 & 3.82 & 4.93 & -1.11 \\
\hline & Q8 & 3.90 & 4.96 & -1.06 \\
\hline \multirow[t]{6}{*}{ Service supply } & Q11 & 3.69 & 4.95 & -1.26 \\
\hline & Q15 & 3.67 & 4.85 & -1.18 \\
\hline & Q16 & 3.70 & 4.86 & -1.16 \\
\hline & Q17 & 3.73 & 4.86 & -1.13 \\
\hline & Q21 & 3.79 & 4.87 & -1.08 \\
\hline & Q23 & 3.70 & 4.87 & -1.17 \\
\hline \multirow[t]{6}{*}{ Empathy } & Q24 & 3.82 & 4.95 & -1.13 \\
\hline & Q25 & 3.70 & 4.92 & -1.22 \\
\hline & Q26 & 3.77 & 4.97 & -1.20 \\
\hline & Q27 & 3.73 & 4.95 & -1.22 \\
\hline & Q28 & 3.79 & 4.94 & -1.15 \\
\hline & Q29 & 3.71 & 4.91 & -1.20 \\
\hline \multirow{6}{*}{$\begin{array}{l}\text { Problem } \\
\text { solving }\end{array}$} & Q9 & 3.80 & 4.91 & -1.11 \\
\hline & Q10 & 3.80 & 4.85 & -1.05 \\
\hline & Q12 & 3.83 & 4.87 & -1.04 \\
\hline & Q13 & 4.02 & 4.98 & -0.96 \\
\hline & Q14 & 3.81 & 4.88 & -1.07 \\
\hline & Q18 & 3.87 & 4.94 & -1.07 \\
\hline \multirow[t]{3}{*}{ Security } & Q19 & 3.97 & 4.94 & -0.97 \\
\hline & Q20 & 3.93 & 4.89 & -0.96 \\
\hline & Q22 & 3.97 & 4.93 & -0.96 \\
\hline
\end{tabular}

Table 4 Level of customer service perception with respect to service quality dimensions

\begin{tabular}{lll}
\hline Dimension & PSQI & Ranking \\
\hline Tangibles & 0.782 & 3 \\
Service & 0.762 & 4 \\
supply & & \\
Empathy & 0.760 & 5 \\
Problem & 0.787 & 2 \\
solving & & \\
Security & 0.804 & 1 \\
\hline
\end{tabular}

virtual input, 1, were assigned as the inputs in the DEA model. Model (6) was solved and PSQI $=0.77$ was determined to represent the efficiency level.

In addition, the proposed model was used to evaluate the service quality in terms of quality dimensions. To accomplish this evaluation, the perceptions and expectations means of each dimension were considered as the outputs of
Table 5 Service quality improvement suggestions for the hotel

\begin{tabular}{|c|c|c|c|c|c|}
\hline Dimension & Item & $P_{Q_{i}}^{\prime}(0.8)$ & $P_{Q_{i}}^{\prime}(0.85)$ & $P_{Q_{i}}^{\prime}(0.9)$ & $P_{Q_{i}}^{\prime}(0.95)$ \\
\hline \multirow[t]{8}{*}{ Tangibles } & Q1 & 3.94 & 4.18 & 4.44 & 4.69 \\
\hline & Q2 & 3.95 & 4.20 & 4.44 & 4.69 \\
\hline & Q3 & 3.92 & 4.17 & 4.42 & 4.67 \\
\hline & Q4 & 3.97 & 4.22 & 4.46 & 4.69 \\
\hline & Q5 & 3.97 & 4.22 & 4.46 & 4.72 \\
\hline & Q6 & 3.92 & 4.17 & 4.42 & 4.67 \\
\hline & Q7 & 3.94 & 4.18 & 4.44 & 4.69 \\
\hline & Q8 & 3.97 & 4.22 & 4.46 & 4.72 \\
\hline \multirow[t]{6}{*}{ Service supply } & Q11 & 3.97 & 4.22 & 4.46 & 4.69 \\
\hline & Q15 & 3.86 & 4.12 & 4.37 & 4.61 \\
\hline & Q16 & 3.88 & 4.12 & 4.37 & 4.61 \\
\hline & Q17 & 3.88 & 4.12 & 4.37 & 4.61 \\
\hline & Q21 & 3.88 & 4.13 & 4.39 & 4.63 \\
\hline & Q23 & 3.88 & 4.13 & 4.39 & 4.63 \\
\hline \multirow[t]{6}{*}{ Empathy } & Q24 & 3.97 & 4.22 & 4.46 & 4.69 \\
\hline & Q25 & 3.94 & 4.18 & 4.42 & 4.67 \\
\hline & Q26 & 3.98 & 4.24 & 4.48 & 4.72 \\
\hline & Q27 & 3.97 & 4.22 & 4.46 & 4.69 \\
\hline & Q28 & 3.95 & 4.20 & 4.44 & 4.69 \\
\hline & Q29 & 3.92 & 4.17 & 4.42 & 4.67 \\
\hline \multirow{6}{*}{$\begin{array}{l}\text { Problem } \\
\text { solving }\end{array}$} & Q9 & 3.92 & 4.17 & 4.42 & 4.67 \\
\hline & Q10 & 3.86 & 4.12 & 4.37 & 4.61 \\
\hline & Q12 & 3.88 & 4.13 & 4.39 & 4.63 \\
\hline & Q13 & 4.02 & 4.24 & 4.48 & 4.74 \\
\hline & Q14 & 3.89 & 4.15 & 4.39 & 4.63 \\
\hline & Q18 & 3.95 & 4.20 & 4.44 & 4.69 \\
\hline \multirow[t]{3}{*}{ Security } & Q19 & 3.97 & 4.20 & 4.44 & 4.69 \\
\hline & Q20 & 3.94 & 4.15 & 4.41 & 4.65 \\
\hline & Q22 & 3.97 & 4.18 & 4.44 & 4.69 \\
\hline
\end{tabular}

All values are rounded to two decimal places

the DMUs separately. The PSQIs of the service factors (Table 4) show the amount of customers' perceptions for the respective service dimension.

The ranking of service quality dimensions shows that the least PSQI is "Empathy" followed in descending order by "Service supply", "Tangibles", "Problem solving", and "Security".

\section{Improvement suggestions}

The efficiency scores of expectations and perceptions for the overall service quality are 1 and 0.77 , respectively. This shows that the overall expectations of customers were not met by the hotel services. The target levels of perceptions from 29 service quality attributes that caused the hotel achieve their DPSQI were calculated by (8) and shown as $P_{Q_{i}}^{\prime}($ DPSQI $)(i=1, \ldots, 29)$ in Table 5. 
It is often difficult to eliminate all quality gaps in a short period of time. However, the information provided by the model could be used by the hotel management to improve their service quality in the long term by focusing on their weaknesses and inefficiencies.

\section{Conclusion and future research directions}

A key challenge for researchers is to accurately devise methods for measuring service quality gaps (Parasuraman et al. 1985). The hybrid DEA-SERVQUAL approach proposed in this study was effectively used to measure the service quality of a hotel in Tehran. Among the various methods of service quality evaluation, SERVQUAL has been widely used in different service industries. The SERVQUAL gap has been used to analyze the level of service quality items, dimensions, or the overall service quality in many studies. Equation (1) which was used to measure the overall service quality does not provide a clear insight into the level of customer perceived service quality. In addition, because of the public tendency to rate the expectation high, the perception scores are dominant contributors to the gap score (Babakus and Boller 1992). The approach proposed in this study addresses this limitation by producing a single measure (PSQI) as the efficiency of the perceptions.

Comparing this integrating measure with the perceived quality that is calculated using Eq. (1), the PSQI shows the level of service quality of the organization clearly and delineates the real distance of the offered service quality to the ideal level. In addition, a proposed NLP model based on the SBM, introduces the improvement guidelines in terms of the items and dimensions of quality to enhance service quality with regards to a set of quality attributes. The proposed method not only analyzes the strengths and weakness of the service organizations, but the integration of service quality and DEA can generate benchmarking guidelines for both perception and expectation of customers.

In this paper, DEA as a non-parametric approach is used to measure the efficiency of DMUs. Therefore, using DEA, the requirements imposed on the distributional properties of the data for conducting parametric statistical tests (e.g., $t$ tests) do not need to be satisfied. Therefore, this method can be used in performance measurement problems with similar statistical limitations.

Furthermore, service quality should be measured periodically to make continuous improvement as a vital part of service management planning. Hence, the ability of assessing service quality as a single and accurate measure is necessary.

Acknowledgments The authors would like to thank the anonymous reviewers and the editor for their insightful comments and suggestions.
Open Access This article is distributed under the terms of the Creative Commons Attribution License which permits any use, distribution, and reproduction in any medium, provided the original author(s) and the source are credited.

\section{References}

Akan P (1995) Dimensions of service quality: a study in Istanbul. Managing Serv Qual 5:39-43

Akbaba A (2006) Measuring service quality in the hotel industry: a study in a business hotel in Turkey. Intern J Hosp Manag 25:170-192

Ariffin AAM, Maghzi A (2012) A preliminary study on customer expectations of hotel hospitality: influences of personal and hotel factors. Intern J Hosp Manag 31:191-198

Armstrong RW, Mok C, Go FM, Chan A (1997) The importance of cross-cultural expectations in the measurement of service quality perceptions in the hotel industry. Intern J Hosp Manag 16:181-190

Assaf AG, Magnini V (2012) Accounting for customer satisfaction in measuring hotel efficiency: evidence from the US hotel industry. Intern J Hosp Manag 31:642-647

Awasthi A, Chauhan SS, Omrani H, Panahi A (2011) A hybrid approach based on SERVQUAL and fuzzy TOPSIS for evaluating transportation service quality. Comput Ind Eng 61:637-646

Babakus E, Boller GW (1992) An empirical assessment of the SERVQUAL scale. J Bus Res 24:253-268

Bahadori M, Sadeghifar J, Nejati M, Hamouzadeh P, Hakimzadeh M (2011) Assessing quality of educational service by the SERVQUAL model: viewpoints of paramedical students at Tehran University of Medical Science. Tech Technol Educ ManagTTEM 6:1058-1065

Batista MG, Couto JP, Botelho D, Faias C (2014) Tourists' satisfaction and loyalty in the hotel business: an application to the island of São Miguel Azores. Tour Manag Stud 10(1):16-23

Bessent A, Bessent W, Elam J, Long D (1984) Educational productivity council employs management science methods to improve educational quality. Interfaces 14:1-8

Bouyssou D (1999) Using DEA as a tool for MCDM: some remarks. J Oper Res Soc 50:974-978

Buttle F (1996) SERVQUAL: review, critique, research agenda. Eur J Mark 30:8-32

Carrasco RA, Muñoz-Leiva F, Sánchez-Fernández J, Liébana-Cabanillas FJ (2012) A model for the integration of e-financial services questionnaires with SERVQUAL scales under fuzzy linguistic modeling. Expert Syst Appl 39:11535-11547

Caruana A, Ewing MT, Ramaseshan B (2000) Assessment of the three-column format SERVQUAL: an experimental approach. J Bus Res 49:57-65

Chang HS (2008) Increasing hotel customer value through service quality cues in Taiwan. Serv Ind J 28:73-84

Charnes A, Cooper WW, Rhodes E (1978) Measuring the efficiency of decision making units. Eur J Oper Res 2:429-444

Chau VS, Kao YY (2009) Bridge over troubled water or long and winding road? Gap-5 in airline service quality performance measures. Manag Serv Qual 19:106-134

Chen CH (2011) Integrating service quality evaluation model to improve employees' satisfaction for high-tech iindustry. Human Factors Erg Manuf Serv Industries 22:517-527

Chen CM, Yeh CY (2011) The causality examination between demand uncertainty and hotel failure: a case study of international tourist hotels in Taiwan. Intern J Hosp Manag 31:1045-1049

Cheng H, Lu YC, Chung (2010) Improved slack-based contextdependent DEA - a study of international tourist hotels in Taiwan. Expert Syst Appl 37, 6452-6458 
Chien CJ, Tsai HH (1998) Using fuzzy numbers to evaluate perceived service quality. Fuzzy Sets Syst 116:289-300

Chilingerian J, Sherman HD (1990) Managing physician efficient and effectiveness in providing hospital services. Health Serv Manag Res 3:3-15

Chiu YH, Ting CT, Huang CW (2010) The different systems for tourist hotels efficiency estimation in Taiwan. Serv Ind J 30:2367-2385

Chou CC (2009) A model for the evaluation of airport service quality. Proc ICE-Trans 162:207-213

Chou CC, Liu LJ, Huang SF, Yih JM, Han TC (2011) An evaluation of airline service quality using the fuzzy weighted SERVQUAL method. Appl Soft Comput 11:2117-2128

Cooper WW, Seiford LM, Tone K (2007) Data envelopment analysis: a comprehensive text with models, applications, references and DEA-solver software. Springer, Berlin

Eiselt HA, Sandblom C-L (2007) Linear programming and its applications. Springer

Ekinci Y, Riley M, Fife-Schaw C (1998) Which school of thought? The dimensions of resort hotel quality. Intern J Contemp Hosp Manag 10:63-67

Fick GR, Ritchie JR (1991) Measuring service quality in the travel and tourism industry. J Travel Res 30:2-9

Gilbert D, Wong RKC (2003) Passenger expectations and airline services: a Hong Kong based study. Tour Manag 24:519-532

Grönroos C (1982) Strategic management and marketing in service sector. Cambridge, MA

Grönroos C (1984) A service quality model and its marketing implications. Eur J Mark 18:36-44

Hosseini MB, Tarokh MJ (2013) Type-2 fuzzy set extension of DEMATEL method combined with perceptual computing for decision making. J Indus Eng Intern 9:1-10

Hsieh LF, Lin LH (2010) A performance evaluation model for international tourist hotels in Taiwan: an application of the relational network DEA. Intern J Hosp Manag 29:14-24

Hsieh LF, Wang LH, Huang YC, Chen A (2010) An efficiency and effectiveness model for international tourist hotels in Taiwan. Serv Indus J 30:2183-2199

$\mathrm{Hu} \mathrm{HH}$, Kandampully J, Juwaheer TD (2009) Relationships and impacts of service quality, perceived value, customer satisfaction, and image: an empirical study. Serv Indus J 29:111-125

Knutson B, Stevens P, Wullaert C, Patton M, Yokoyama F (1990) LODGSERV: a service quality index for the lodging industry. Hosp Res J 14:227-284

Kumar M, Kee FT, Manshor AT (2009) Determining the relative importance of critical factors in delivering service quality of banks An application of dominance. Manag Serv Qual 19:211-228

Kuo CM, Chen LC, Lu CY (2012) Factorial validation of hospitality service attitude. Intern J Hosp Manag 31:944-951

Kwortnik RJ, Han X (2011) The Influence of Guest Perceptions of Service Fairness on Lodging Loyalty in China. Cornell Hosp Quar 52:321-332

Ladhari R (2009) Service quality, emotional satisfaction, and behavioural intentions A study in the hotel industry. Manag Serv Qual 19:308-331

Ladhari R (2011) The lodging quality index: an independent assessment of validity and dimensions. Intern J Contemp Hosp Manag 24:628-652

Lee H, Kim C (2012) A DEA-SERVQUAL approach to measurement and benchmarking of service quality the 2012 International (Spring) Conference on Asia Pacific Business Innovation and Technology Management Procedia-Social and Behavioral Sciences, pp 756-762

Lee H, Kim C (2014) Benchmarking of service quality with data envelopment analysis. Expert Syst Appl 41:3761-3768
Lin HT (2010) Fuzzy application in service quality analysis: an empirical study. Expert Syst Appl 37:517-526

Lovell CAK, Pastor JT (1997) Target setting: an application to a bank branch network. Eur J Oper Res 98:290-299

Lovell CAK, Pastor JT (1999) Radial DEA models without inputs or without outputs. Eur J Oper Res 118:46-51

Lupo T (2013) A fuzzy ServQual based method for reliable measurements of education quality in Italian higher education area. Expert Syst Appl 40:7096-7110

Manandhar R, Tang JSC (2002) The evaluation of bank branch performance using data envelopment analysis A framework. J High Technol Manag Res 13:1-17

Martín-Cejas RR (2006) Tourism service quality begins at the airport. Tour Manag 25:874-877

Mei AWO, Dean AM, White CJ (1999) Analyzing service quality in the hospitality industry. Manag Serv Qual 9:136-143

Monfared MAS, Safi M (2013) Network DEA: an application to analysis of academic performance. J Indus Eng Intern 9:1-10

Najafi S, Saati S, Bighami MK, Abdi F (2013) How do customers evaluate hotel service quality? An empirical study in Tehran hotels. Manag Sci Lett 3:3019-3030

Nasrabadi AM, Hosseinpour MH, Ebrahimnejad S (2013) Strategyaligned fuzzy approach for market segment evaluation and selection: a modular decision support system by dynamic network process (DNP). J Indus Eng Intern 9:1-17

Opricovic S (1998) Multicriteria optimization in civil engineering (in Serbian). Faculty of Civil Engineering, Belgrade

Parasuraman A, Zeithaml VA, Berry LL (1985) A conceptual model of service quality and its implications for future research. J Market 49:41-50

Ro H, Wong J (2012) Customer opportunistic complaints management: a critical incident approach. Intern J Hosp Manag 31:419-427

Saleh F, Ryan C (1991) Analyzing service quality in the hospitality industry using the SERVQUAL model. Serv Indus J 11:324-343

Satapathy S, Mishra P (2013) A customer oriented systematic framework to extract business strategy in Indian electricity services. J Indus Eng Intern 9:33

Seol H, Choi J, Park G, Park Y (2007) A framework for benchmarking service process using data envelopment analysis and decision tree. Expert Syst Appl 32:432-440

Sherman HD, Zhu J (2006) Benchmarking with quality-adjusted DEA (Q-DEA) to seek lower-cost high-quality service: evidence from a U.S.bank application. Ann Oper Res 145:301-319

Shieh JI, Wu HH, Huang KK (2010) A DEMATEL method in identifying key success factors of hospital service quality. Knowledge-Based Syst 23:277-282

Shyu J, Hung SC (2012) The true managerial efficiency of international tourist hotels in Taiwan: three-stage data envelopment analysis. Serv Indus J 32:1991-2004

Sigala M (2004) Using data envelopment analysis for measuring and benchmarking productivity in the hotel sector. J Travel Tour Market 16:39-60

Soteriou A, Stavrinides Y (1997) An internal customer service quality data envelopment analysis model for bank branches. Intern J Oper Prod Manag 17:780-789

Soteriou A, Zenios S (1999) Operations, quality, and profitability in the provision of banking services. Management Science 45:1221-1238

Stauss B, Weinlich B (1997) Process-oriented measurement of service quality: applying the sequential incident technique. Eur J Market 31:33-55

Talluri S, Kim MK, Schoenherr T (2013) The relationship between operating efficiency and service quality: are they compatible? Intern J Prod Res 51:2548-2567 
Tone K (2001) A slack-based measure of super-efficiency in data envelopment analysis. Eur J Oper Res 130:498-509

Tsang N, Qu H (2000) Service quality in China's hotel industry: a perspective from tourists and hotel managers. Intern J Contemp Hosp Manag 12:316-326

Wilkins H, Merrilees B, Herington G (2007) Towards an understanding of total service quality in hotels. Intern $\mathrm{J}$ Hosp Manag 26:840-853

Wu WY, Hsiao SW, Kuo HP (2004) Fuzzy set theory based decision model for determining market position and developing strategy for hospital service quality. Total Qual Manag 15:439-456
Yang CC, Jou YT, Cheng LY (2011) Using integrated quality assessment for hotel service quality. Qual Quan 45:349-364

Zarei A, Arab M, Froushani AR (2012) Service quality of private hospitals: The Iranian Patients' perspective. BMC Health Services Research 12

Zoraghi N, Amiri M, Talebi G, Zowghi M (2013) A fuzzy MCDM model with objective and subjective weights for evaluating service quality in hotel industries. J Indus Eng Intern 9:38 